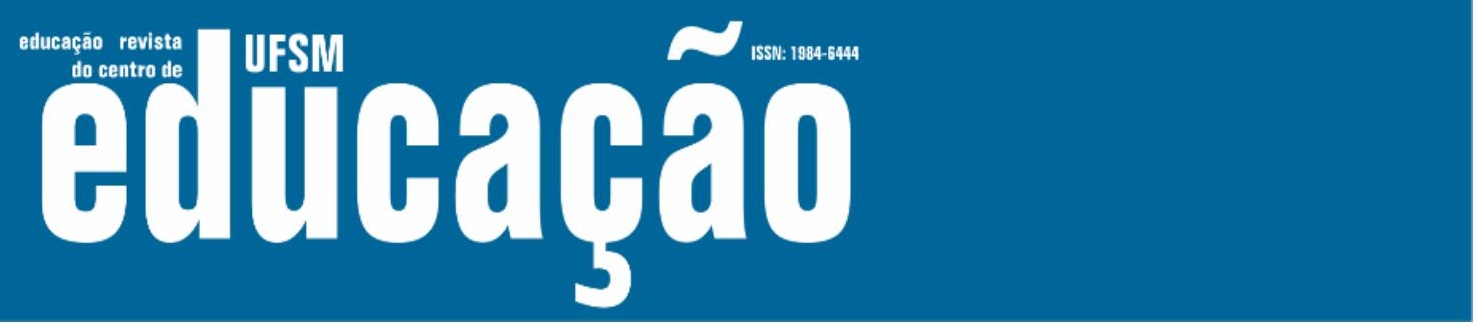

ISSN: 1984-6444 | http://dx.doi.org/10.5902/1984644442721

\title{
Infraestrutura das creches e pré-escolas em Belo Horizonte: condições de oferta e distribuição territorial
}

\author{
Early childhood education infrastructure in Belo Horizonte: offer \\ conditions and territorial distribution
}

Franceline Rodrigues Silva

Doutoranda na Universidade Federal de Minas Gerais, Belo Horizonte, Minas Gerais, Brasil. franceline.rodrigues30@gmail.com - https://orcid.org/0000-0003-0213-3192

Daniel Santos Braga

Doutorando na Universidade Federal de Minas Gerais, Belo Horizonte, Minas Gerais, Brasil. danielsantosbraga@gmail.com - http://orcid.org/0000-0001-5075-4570

Lívia Maria Fraga Vieira

Professora doutora na Universidade Federal de Minas Gerais, Belo Horizonte, Minas Gerais, Brasil. liviafraga59@gmail.com - https://orcid.org/0000-0002-9036-0151

Recebido em 04 de março de 2020

Aprovado em 09 de abril de 2020

Publicado em 31 de janeiro de 2021

\section{RESUMO}

Este artigo tem como objetivo discutir as condições de oferta da educação infantil em Belo Horizonte em relação à sua estrutura física e distribuição territorial. Foram utilizadas como fontes de dados o Censo Escolar do Instituto Nacional de Estudos e Pesquisas Educacionais Anísio Teixeira do ano de 2018 e o Atlas Brasil. A construção dos indicadores de adequação das condições de oferta foi feita por uma escala numérica contínua aferida para melhor se adequar aos propósitos deste estudo tendo como unidade de análise as escolas de educação infantil públicas e privadas (conveniadas ao poder público ou não) e sua relação com a Unidade de Desenvolvimento Humano à qual pertencia. O estudo permitiu constatar que muitas escolas de educação infantil de Belo Horizonte não apresentam todas as condições de infraestrutura em níveis satisfatórios. Por outro lado, evidenciou que a distribuição territorial das creches e pré-escolas corresponde satisfatoriamente à demanda, sendo que as escolas públicas estão presentes nas áreas com maiores necessidades de atendimento por parte do Estado.

Palavras-chave: Educação infantil; Condições de oferta educacional; Infraestrutura de escolas; Belo Horizonte 


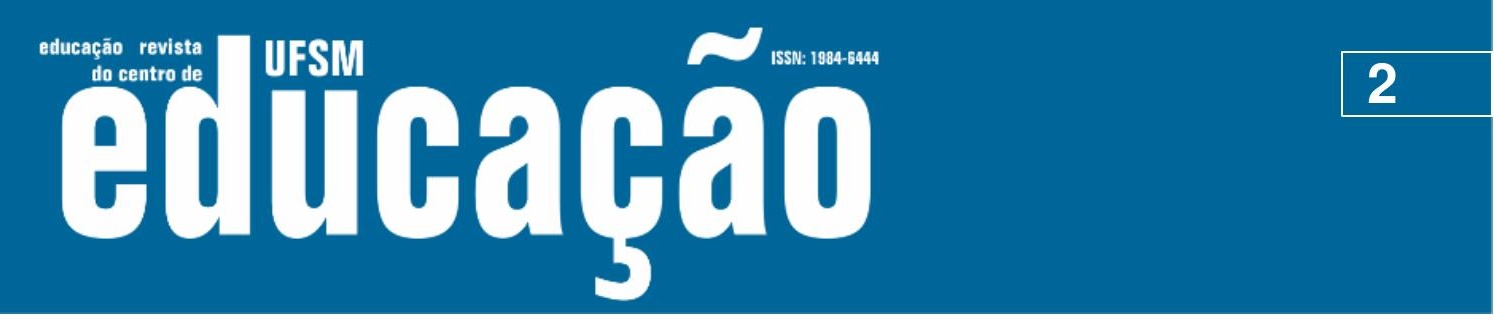

ISSN: 1984-6444 | http://dx.doi.org/10.5902/1984644442721

\section{ABSTRACT}

This article aims at discussing the offer conditions for early childhood education in Belo Horizonte concerning its physical structure and territorial distribution. The National Institute of Educational Studies and Research's 2018 School Census and Atlas Brasil were used as data sources. The construction of the supply conditions adequacy indicators was made by a continuous numerical scale measured to better fit the purposes of this study having as unit of analysis the public and private schools of infant education (convened to the public power or not) and its relationship with the Human Development Unit to which it belonged. The main findings of this study are the evidence of the Belo Horizonte' early childhood education precarious supply conditions schools, as well as their unequal territorial distribution, taking into account the needs of the population of regulatory age for this stage.

Keywords: Early childhood education; Educational offer conditions; School infrastructure; Belo Horizonte.

\section{Introdução}

A Constituição Federal de 1988 e a Lei de Diretrizes e Bases da Educação Nacional (LDB), promulgada em 1996, são importantes marcos na trajetória histórica pela democratização do acesso à educação escolar no Brasil. Pela primeira vez na história do país, a educação é estabelecida como um direito público subjetivo, e o dever do Estado é afirmado e ampliado para a garantia deste direito. Além disso, a educação escolar de crianças de zero a cinco anos, a educação infantil, é integrada aos sistemas de ensino, compondo com o ensino fundamental e médio, a educação básica. Os Planos Nacionais de Educação - PNEs de 2001 (Lei 10.172) e 2014 (Lei 13.005), aprovados conforme exigência da LDB, traçaram metas decenais para ampliação da oferta e do acesso a essa etapa da educação básica, buscando realizar as garantias constitucionais.

Entretanto, estudos apontam que o país está longe de cumprir as metas estabelecidas pelos planos decenais (OCDE, 2017; OBSERVATÓRIO, 2018) permanecendo excluídas da educação escolar em 2017 um número significativo de crianças de quatro e cinco anos (cerca de 9,5\% - 500 mil crianças) e um número maior de crianças de zero a três anos (cerca de 69,6\% - déficit de 2,4 milhões de vagas). Ainda que nas últimas décadas tenha existido um esforço para superar os obstáculos 


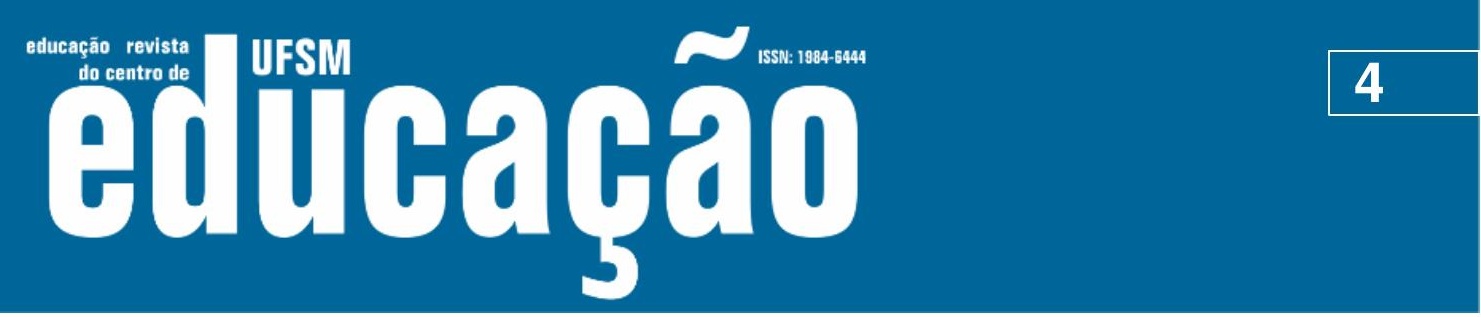

ISSN: 1984-6444 | http://dx.doi.org/10.5902/1984644442721

infantil em Belo Horizonte passou a ser ofertada por diferentes tipos de instituições. As públicas, com as UMEls, as pré-escolas municipais (antigos jardins municipais), as escolas de ensino fundamental com turmas de educação infantil. As privadas, sendo as creches e pré-escolas conveniadas com a prefeitura, além das particulares ou filantrópicas/comunitárias não conveniadas com o poder público municipal.

Diante de um contexto de grande déficit de vagas em escolas para crianças de zero a cinco anos, o PNE 2014-2024 estabeleceu em sua Meta 1 a universalização do acesso às pré-escolas e a ampliação da oferta nas creches, de forma a atender, no mínimo, 50\% das crianças de zero a três anos até 2024 . Além disso, a Meta 7 definiu o fomento à qualidade em todas as etapas da educação básica, incluindo a educação infantil. Uma das estratégias para esse esforço encontra-se na determinação de padrões mínimos de qualidade dos serviços da educação básica a serem utilizados como referência para infraestrutura das escolas, incluindo também recursos pedagógicos, entre outros insumos relevantes (estratégia 7.21).

Levando em conta a coexistência de distintas iniciativas e tipologias de estabelecimentos de educação infantil em Belo Horizonte, o objetivo deste artigo é analisar as condições de oferta das creches e pré-escolas no município. Para isso, foram utilizados os dados do Censo Escolar do ano de 2018 (formulário das turmas e das escolas), realizado sob a responsabilidade do Instituto Nacional de Pesquisas Educacionais Anísio Teixeira (INEP). O artigo foi dividido em duas partes. Na primeira, buscou-se apresentar uma discussão sobre a especificidade jurídica da educação infantil, assim como o seu desenvolvimento histórico no município de Belo Horizonte. $\mathrm{Na}$ segunda parte, foi traçado o perfil das condições de oferta da educação infantil no município de acordo com dois parâmetros: infraestrutura dos estabelecimentos e sua distribuição territorial.

\section{A educação infantil e sua trajetória em Belo Horizonte}

A educação infantil, hoje composta pelos segmentos de creches e pré-escolas, estabelecida no espaço escolar e no sistema educacional, é uma construção social e histórica. 


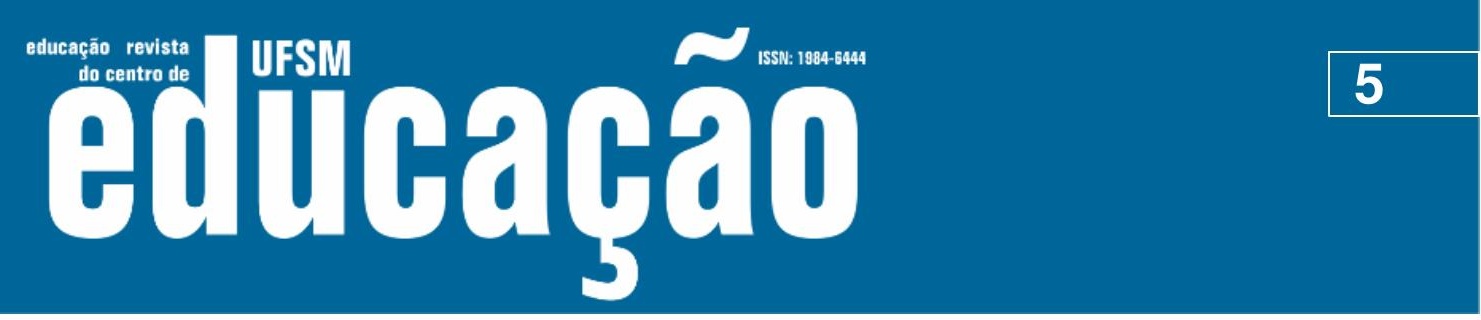

ISSN: 1984-6444 | http://dx.doi.org/10.5902/1984644442721

O atendimento público na Rede Municipal de Educação de Belo Horizonte (RME/BH) fora iniciado em 1957, quando da inauguração do Jardim Municipal Renascença (BELO HORIZONTE, 2016). De 1957 até o ano de 2003, o atendimento proporcionado às crianças pequenas na $\mathrm{RME} / \mathrm{BH}$ se deu apenas para a faixa etária de quatro a seis anos, em horário parcial, nas escolas municipais de educação préescolar (chamadas de jardins municipais) e em escolas municipais do ensino fundamental, nas quais funcionavam turmas de educação infantil. As matrículas na rede municipal até o início dos anos 2000 não chegava a 5.000 crianças naquela faixa de idade.

Até 2004 , as crianças de zero a três anos de idade não eram contempladas pela rede pública municipal de Belo Horizonte. Inicialmente, nas décadas de 1950 e 1960, esse atendimento realizava-se em poucas creches de origem filantrópica. No final dos anos de 1970, novas iniciativas foram vislumbradas com a emergência das creches comunitárias na região industrial de Belo Horizonte (SILVA, 2002; TERRA, 2008), motivadas pelo movimento de mães trabalhadoras que reivindicavam um lugar de guarda e educação para os seus filhos, para poderem trabalhar, sendo muitas delas as únicas responsáveis pelo sustento da família.

A precariedade de políticas públicas educacionais para as crianças pequenas na cidade levou, pela mobilização de mulheres engajadas em grupos de apoio como as comunidades eclesiais de base e outros setores sociais, à criação do Movimento de Luta Pró-Creche (MLPC), que objetivava, em um primeiro momento, obter recursos financeiros para manutenção das creches (SILVA, 2008). Em 1983 foi assinado o primeiro convênio da Prefeitura de Belo Horizonte com essas creches, por intermédio da Secretaria de Saúde (VEIGA, 2005). A partir desta data esta política de convênios foi se consolidando no âmbito do município, passando a ser administrada pela área da assistência social. Persiste até os dias atuais. Administrada pela Secretaria de Educação, a partir de 2002, a política de convênios vem sendo sistematicamente fortalecida como uma das modalidades de oferta de educação infantil em Belo Horizonte, subsidiada com recursos públicos financeiros e técnicos.

Dialogando com os avanços da legislação nacional em relação às creches e pré-escolas e em direção ao reconhecimento da educação infantil como uma etapa 


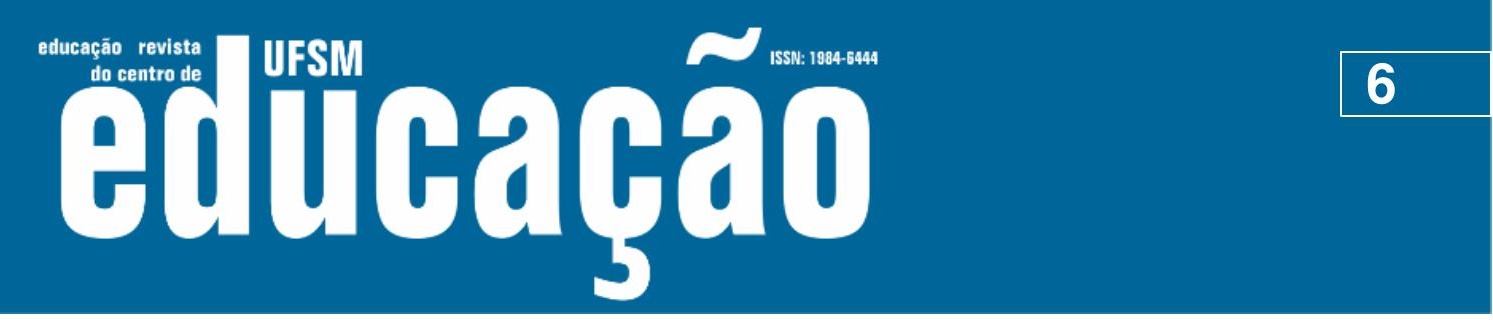

ISSN: 1984-6444 | http://dx.doi.org/10.5902/1984644442721

da educação básica, em 21 de março de 1990 é promulgada a Lei Orgânica do Município de Belo Horizonte e, posteriormente em 1998, é constituído o Sistema Municipal de Ensino de Belo Horizonte (SME/BH), sancionado pela prefeito Célio de Castro com a Lei no 7.543, de 30 de junho de 1998. Um impacto direto da criação do $\mathrm{SME} / \mathrm{BH}$ na educação infantil foi a transferência do gerenciamento dos convênios com 176 creches da Secretaria Municipal de Assistência Social para a Secretaria Municipal de Educação, no ano de 2002 (TERRA, 2008).

O estabelecimento de novas bases para a política de educação infantil visando a melhoria das condições da oferta educacional nesta etapa da educação básica, incluindo a oferta pública de creches, se expressou na aprovação, em 11 de novembro de 2003, da Lei ํㅜ 8.679/2003. Por meio dessa lei são criadas as UMEls e instituído o cargo de Educador Infantil (BELO HORIZONTE, 2003). Até essa data, a ampliação do atendimento às crianças na faixa etária da educação infantil efetuado pela Prefeitura de Belo Horizonte acontecia predominantemente por meio dos convênios com instituições comunitárias e filantrópicas (PINTO, 2009). As UMEls, como indica a legislação municipal, foram criadas com a finalidade de garantir pleno atendimento educacional às crianças de até 5 (cinco) anos e 8 (oito) meses de idade. Neste intuito, foram também consideradas uma referência no país pelo projeto arquitetônico adotado, como se destaca a seguir:

[...] Isso se dá em função de que, pela primeira vez no município, uma equipe interdisciplinar (formada por arquitetos, engenheiros, pedagogos e outros profissionais) se reuniu para pensar, arquitetar e construir um padrão de instituição que fosse sensível às necessidades das crianças em termos de cuidado e educação. Exemplo maior da grandeza desse programa de construção de instituições de Educação infantil é o fato de que ele se tornou referência obrigatória no Ministério da Educação, tanto que o projeto arquitetônico das UMEls de Belo Horizonte está presente nos Parâmetros Básicos de Infraestrutura para Instituições de Educação infantil como exemplo de construção para todo o país (SANTOS, 2017, n.p, grifos nossos).

Três anos antes da criação das UMEls, o Conselho Municipal de Educação vota a Resolução CME/BH nº 01/2000, substituída, em 2015, pela Resolução nº 001/2015, fixando as normas para a criação e o funcionamento das instituições de educação infantil no Sistema Municipal de Ensino de Belo Horizonte (BELO HORIZONTE, 2015). Ambas as resoluções trazem determinações relativas aos 


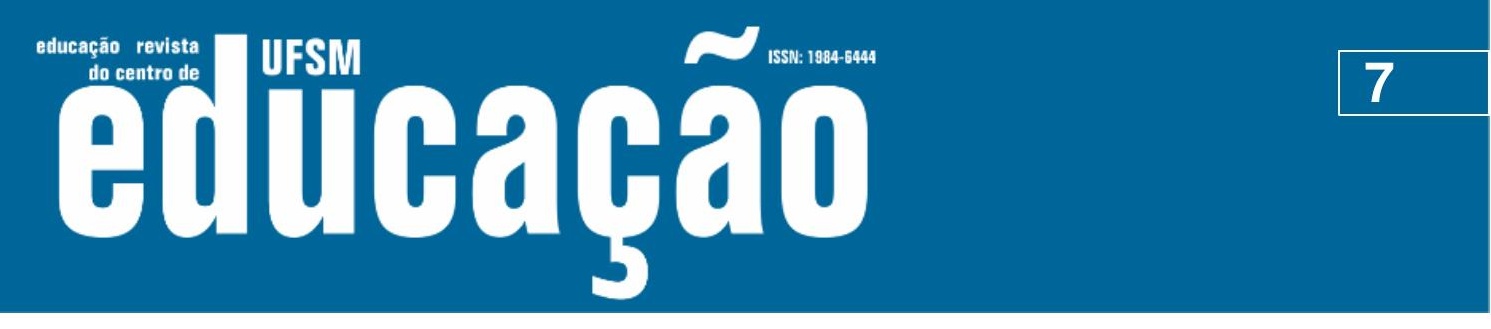

ISSN: 1984-6444 | http://dx.doi.org/10.5902/1984644442721

espaços físicos, instalações e equipamentos dessas instituições educacionais, apresentadas no Quadro 1 abaixo:

Quadro 1 -Determinações legais para os espaços, instalações e equipamentos de instituições de educação infantil de Belo Horizonte

\begin{tabular}{|c|c|}
\hline Resolução CME/BH no 01/2000 (art. 14) & Resolução CME/BH no 001/2015 (art. 50) \\
\hline Espaço para recepção; & Recepção; \\
\hline $\begin{array}{l}\text { Sala de professores, para serviço } \\
\text { administrativo-pedagógico e de apoio; }\end{array}$ & $\begin{array}{l}\text { Sala própria para atividades administrativas e } \\
\text { pedagógicas/ sala de professores; }\end{array}$ \\
\hline $\begin{array}{l}\text { Salas para as atividades das crianças, com } \\
\text { ventilação adequada, iluminação natural e } \\
\text { artificial e visão para o ambiente externo, com } \\
\text { mobiliário e equipamentos adequados; }\end{array}$ & $\begin{array}{l}\text { Salas para atividade das crianças, com } \\
\text { dimensões que garantam, no mínimo, } 1 \mathrm{~m}^{2} \text { (um } \\
\text { metro quadrado) por criança, com ventilação } \\
\text { direta e iluminação natural, que podem ser } \\
\text { complementadas com a artificial; }\end{array}$ \\
\hline $\begin{array}{l}\text { Refeitório, instalações e equipamentos para o } \\
\text { preparo de alimentos, que atendam às } \\
\text { exigências de nutrição, saúde, higiene e } \\
\text { segurança, nos casos de oferta de } \\
\text { alimentação; }\end{array}$ & $\begin{array}{l}\text { Refeitório/ Instalações, equipamentos e } \\
\text { condições para o preparo e/ou fornecimento } \\
\text { de alimentos, que atendam às exigências de } \\
\text { nutrição, saúde, higiene e segurança; }\end{array}$ \\
\hline $\begin{array}{l}\text { Disponibilidade de água potável para consumo } \\
\text { e higienização; }\end{array}$ & $\begin{array}{l}\text { Instalação de água potável para consumo e } \\
\text { higienização, acessível às crianças; }\end{array}$ \\
\hline $\begin{array}{l}\text { Instalações sanitárias completas, adequadas e } \\
\text { suficientes para atender separadamente } \\
\text { crianças e adultos; }\end{array}$ & $\begin{array}{l}\text { Banheiros infantis adequados às faixas etárias } \\
\text { atendidas, com portas desprovidas de chaves } \\
\text { e trincos, que garantam a proporção de: } 1 \text { (um) } \\
\text { vaso sanitário para cada } 20 \text { (vinte) crianças; } 1 \\
\text { (um) lavatório para cada } 20 \text { (vinte) crianças; } \\
\text { chuveiros em quantidade suficiente para } \\
\text { atender a rotina de banho definida pela } \\
\text { instituição, tendo como parâmetro } 1 \text { (um) } \\
\text { chuveiro para cada } 20 \text { (vinte) crianças;/ } \\
\text { Banheiros, para uso exclusivo de adultos, com } \\
\text { instalações sanitárias completas;/ }\end{array}$ \\
\hline $\begin{array}{l}\text { Área com incidência direta de raios de sol ou } \\
\text { espaço externo que atenda a essa } \\
\text { necessidade; }\end{array}$ & $\begin{array}{l}\text { Mobiliário e equipamentos adequados às } \\
\text { atividades pedagógicas, em quantidade } \\
\text { suficiente e tamanho proporcional à faixa } \\
\text { etária atendida, não se constituindo em } \\
\text { obstáculo nem cerceamento à liberdade de } \\
\text { movimento das crianças/ Banheiro infantil } \\
\text { equipado para atender crianças com } \\
\text { deficiência ou adaptações nos banheiros } \\
\text { existentes; }\end{array}$ \\
\hline Área de serviço, lavanderia; & $\begin{array}{l}\text { Área de serviço/lavanderia devidamente } \\
\text { equipada com tanque; depósito de material de } \\
\text { limpeza e armário para guardar vassouras, } \\
\text { rodos e similares, adequados e em bom } \\
\text { estado de conservação e segurança; local } \\
\text { adequado para depósito de lixo, que não } \\
\text { permita o acesso das crianças; }\end{array}$ \\
\hline
\end{tabular}

Educação | Santa Maria | v. 46 |2021

Disponível em: https://periodicos.ufsm.br/reveducacao 


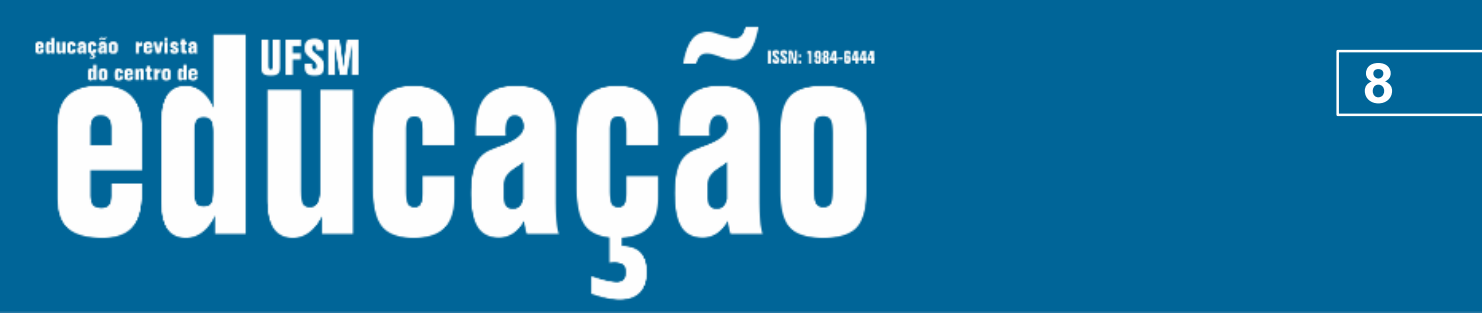

ISSN: 1984-6444 | http://dx.doi.org/10.5902/1984644442721

Continuação Quadro 1 -Determinações legais para os espaços, instalações e equipamentos de instituições de educação infantil de Belo Horizonte

\begin{tabular}{|c|c|}
\hline $\begin{array}{l}\text { Área coberta para atividades externas } \\
\text { compatível com a capacidade de atendimento, } \\
\text { por turno, da instituição. }\end{array}$ & $\begin{array}{l}\text { Espaço externo organizado com: } \\
\text { a) área com incidência direta de raios solares; } \\
\text { b) área coberta; } \\
\text { c) área verde; } \\
\text { d) parque infantil. }\end{array}$ \\
\hline \multicolumn{2}{|l|}{$\begin{array}{l}\text { Berçário provido de berços individuais, com } \\
\text { espaço mínimo de meio metro entre eles, } \\
\text { dentro das normas de segurança específicas } \\
\text { para este mobiliário, com área livre para } \\
\text { movimentação das crianças, locais para } \\
\text { amamentação e para higienização de } \\
\text { utensílios, com balcão e pia, espaço } \\
\text { próprio para banho das crianças; }\end{array}$} \\
\hline 一 & $\begin{array}{l}\text { Sala multiuso destinada a atividades } \\
\text { diferenciadas, planejadas de acordo com a } \\
\text { proposta pedagógica, com equipamentos e } \\
\text { acessórios adequados; }\end{array}$ \\
\hline - & $\begin{array}{l}\text { Biblioteca ou cantinhos de leitura nas salas de } \\
\text { atividade ou sala multiuso. }\end{array}$ \\
\hline - & $\begin{array}{l}\text { Materialidade, jogos e brinquedos adequados } \\
\text { à faixa etária atendida, em boas condições de } \\
\text { uso e segurança incluindo os que valorizem a } \\
\text { diversidade étnico racial. }\end{array}$ \\
\hline \multicolumn{2}{|c|}{$\begin{array}{l}\text { ESPAÇOS PRÓPRIOS PARA INSTITUIÇÃO QUE ATENDER CRIANÇAS DE } 0 \text { (ZERO) A } 2 \text { (DOIS) } \\
\text { ANOS DE IDADE }\end{array}$} \\
\hline 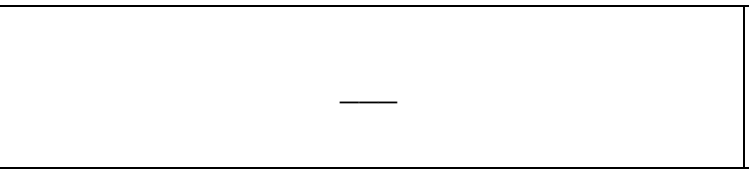 & $\begin{array}{l}\text { Ambiente para repouso provido de berços } \\
\text { individuais ou similares, que respeitem a } \\
\text { distância mínima de } 50 \text { (cinquenta) } \\
\text { centímetros entre eles e as paredes; }\end{array}$ \\
\hline - & $\begin{array}{l}\text { Ambiente que possibilite a movimentação e } \\
\text { estimulação das crianças; }\end{array}$ \\
\hline- & $\begin{array}{l}\text { Solário próprio ou área livre para o banho de } \\
\text { sol }\end{array}$ \\
\hline & $\begin{array}{l}\text { Local para banho e de troca de roupa das } \\
\text { crianças, com lavatório para utilização dos } \\
\text { adultos; }\end{array}$ \\
\hline - & $\begin{array}{l}\text { Local para guardar os materiais de higiene de } \\
\text { uso individual das crianças; }\end{array}$ \\
\hline & Lactário; \\
\hline & $\begin{array}{l}\text { Materialidade e brinquedos adequados à faixa } \\
\text { etária atendida, em boas condições de uso e } \\
\text { segurança incluindo os que valorizam a } \\
\text { diversidade étnico racial. }\end{array}$ \\
\hline
\end{tabular}

Fonte: Elaboração própria a partir das informações disponíveis nas Resoluções do Conselho Municipal de Educação (2000, 2015). 


\section{تilfoarẫ}

ISSN: 1984-6444 | http://dx.doi.org/10.5902/1984644442721

arquitetura do prédio e suas diversas dependências; e equipamentos para o desenvolvimento de práticas didático-pedagógicas. Informações como sexo, idade, cor/etnia dos estudantes matriculados no ano do recenseamento integram o formulário das matrículas. A pesquisa se utilizou desses componentes para avaliar a adequação das condições de oferta das escolas de educação infantil de Belo Horizonte quanto à infraestrutura.

Para delimitar a espacialidade dentro do município, a pesquisa se utilizou das Unidades de Desenvolvimento Humano (UDH) catalogadas pelo Atlas Brasil, a partir de dados do Censo Demográfico do Instituto Brasileiro de Geografia e Estatística (IBGE) de 2010. A UDH é um recorte espacial construído com o objetivo de captar a diversidade de situações relacionadas com o desenvolvimento humano no interior dos espaços intrametropolitanos, especialmente em seus grandes municípios (ATLAS, 2014). Foi proposta uma configuração desses espaços intrametropolitanos, respeitando os critérios e exigências do IBGE, os quais deveriam ser os mais homogêneos possíveis, em termos socioeconômicos (homogeneidade), contíguos (contiguidade) e que fossem reconhecidos por parte da população residente (identidade) (ATLAS, 2014). O município de Belo Horizonte constava, em 2010, com 277 UDH. Como descrito acima, as fronteiras das UDH não coincidem com as dos bairros uma vez que seus autores desejavam agregar características mais homogêneas das regiões.

Belo Horizonte, no Censo Escolar de 2018, contava com 873 escolas ativas com oferta de educação infantil. Destas, 833 atendiam crianças de zero a três anos e 830 atendiam crianças de quatro e cinco anos. Ambos os segmentos, creches e préescolas, estavam presentes em $90 \%$ delas.

Quanto à dependência administrativa, as escolas estavam distribuídas da seguinte forma: 


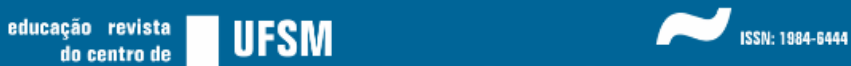

ISSN: 1984-6444 | http://dx.doi.org/10.5902/1984644442721

Tabela 1 - Distribuição de frequência das escolas de educação infantil em Belo Horizonte quanto à dependência administrativa, 2018

\begin{tabular}{lcc}
\hline $\begin{array}{c}\text { Dependência } \\
\text { Administrativa }\end{array}$ & Frequência & $\%$ \\
\hline Municipal & 186 & $21,3 \%$ \\
Privada & 687 & $78,7 \%$ \\
Total & 873 & $100 \%$ \\
\hline
\end{tabular}

Fonte: Censo Escolar/INEP, 2018

Dessa maneira, 21,3\% das escolas de educação infantil em Belo Horizonte eram públicas, sendo mantidas pela rede municipal de ensino. Das 186 escolas municipais, 131 eram UMEls e 14 eram escolas que atendiam exclusivamente educação infantil, mas que não eram classificadas como UMEls. Quarenta e duas eram escolas multietapas que atendiam tanto segmentos da educação infantil quanto do ensino fundamental: dezenove escolas ofertavam os anos iniciais e 23 , os anos finais dessa etapa. 22 escolas ainda contavam com a modalidade de Educação de Jovens e Adultos.

As escolas privadas eram distribuídas quanto ao tipo da seguinte forma:

Tabela 2 - Distribuição das escolas privadas de educação infantil de Belo Horizonte quanto à categoria, 2018

\begin{tabular}{c|c|c}
\hline Categoria & Frequência & $\%$ \\
\hline Particular & 456 & $66,4 \%$ \\
Filantrópica & 151 & $22,0 \%$ \\
Comunitária & 73 & $10,6 \%$ \\
Confessional & 7 & $1,0 \%$ \\
Total & 687 & $100 \%$ \\
\hline Fonte: Censo Escolar/INEP, 2018
\end{tabular}

As escolas privadas ainda podem ser classificadas quanto à presença de convênio com o poder público, sendo a distribuição de frequência em Belo Horizonte, em 2018, disposta da seguinte forma: 


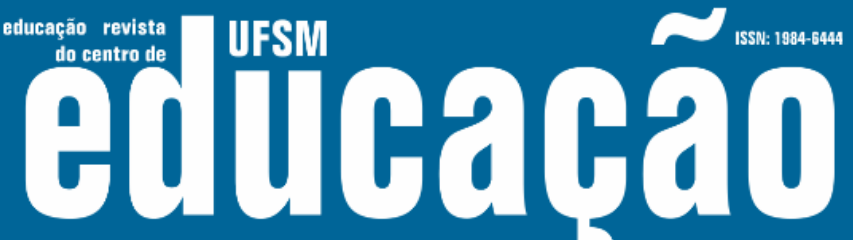

ISSN: 1984-6444 | http://dx.doi.org/10.5902/1984644442721

Figura 1 - Mapa temático de Belo Horizonte da população de 0 a 5 anos e do número de escolas por UDH

\section{$N^{N}$ \\ Legenda}

Número de escolas por UDH

- Nenhuma escola

- Entre 1 e 3 escolas

- Entre 4 e 6 escolas

- Entre 7 e 9 escolas

- Entre 10 e 12 escolas

Acima de 12 escolas

População de 0 a 5 anos

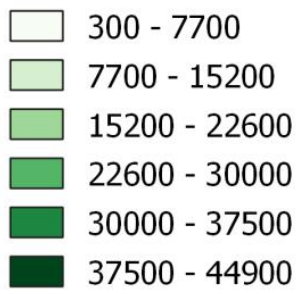

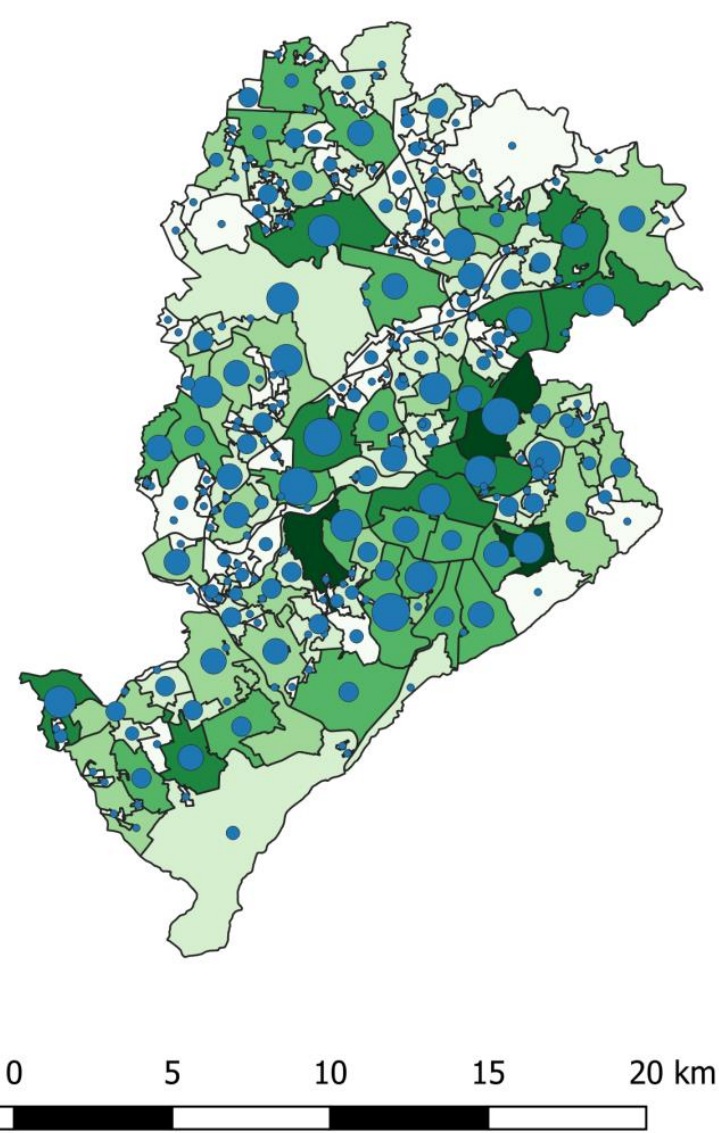

Fonte: Censo Escolar/INEP, 2018; Atlas Brasil, 2014

Quando consideradas apenas as escolas públicas, estas estavam equitativamente distribuídas territorialmente, podendo ser encontradas em todas as nove regionais da capital de Minas Gerais. Com poucas exceções, o maior número de escolas públicas em uma UDH também coincidia com as UDH da cidade com maior população de zero a cinco anos. Sua localização também estava distribuída em consonância com a renda per capita na cidade, estando mais presentes em áreas de maior vulnerabilidade social, como pode ser visto na Figura 2. 


\section{Ailloapẫ}

ISSN: 1984-6444 | http://dx.doi.org/10.5902/1984644442721

Figura 2 - Mapa temático de Belo Horizonte de localização de escolas públicas em relação à renda per capita em $\mathrm{R} \$$ (deflacionada) por UDH
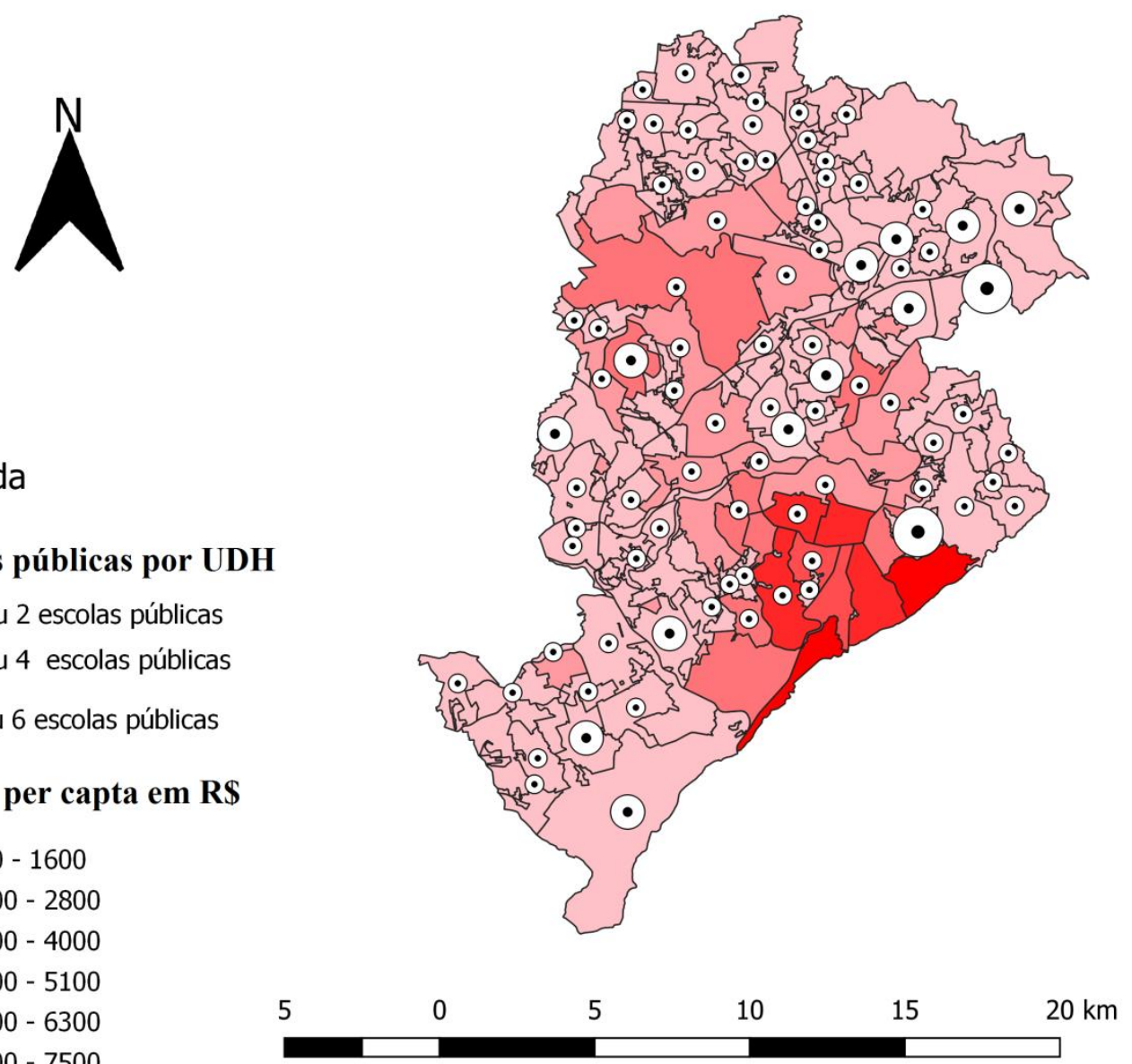

Fonte: Censo Escolar/INEP, 2018; Atlas Brasil, 2014

Em relação à infraestrutura das escolas de educação infantil, a pesquisa considerou uma escala construída por Duarte, Gomes e Gotelipe (2019), de medição da adequação da escola. Nessa escala, os critérios estabelecidos para a construção das variáveis de referência objetivaram ponderar a qualidade da infraestrutura a partir da articulação de itens presentes no Censo Escolar (DUARTE; GOMES; GOTELIPE, 2019).

No formulário das escolas, os autores selecionaram 32 variáveis, que foram agrupadas em três conjuntos: i) atendimento de serviços públicos (água, energia, saneamento e alimentação); ii) instalações físicas e; iii) equipamentos de uso 


\section{T usm

ISSN: 1984-6444 | http://dx.doi.org/10.5902/1984644442721

administrativo e/ou pedagógico. Após a ponderação pela complementaridade dos itens, os valores atribuídos geraram 16 variáveis de referência numéricas, discretas e ordinais (DUARTE; GOMES; GOTELIPE, 2019). Com a aplicação da análise fatorial, pelo método das componentes principais, com rotação ortogonal (varimax) e método de k-médias, os pesquisadores obtiveram três fatores para explicação de variância, sendo que o primeiro, por responder por $44,2 \%$ da variância foi utilizado como índice de avaliação da infraestrutura.

No entanto, a escala elaborada por Duarte, Gomes e Gotelipe se referia ao ensino fundamental, o que levou os autores a excluírem itens específicos de outras etapas, como os relativos à educação infantil. Nesse sentido, esta pesquisa adaptou a escala para analisar aspectos da educação infantil, tais como presença de banheiros específicos para educação infantil e parques infantis, a partir dos elementos presentes no artigo 50 da Resolução CME/BH no 001/2015. Da mesma forma, foram desconsiderados itens que, apesar de poderem fazer parte dos processos da educação infantil, não são fundamentais para que ele ocorra, não constando, por exemplo, nos Parâmetros básicos de infraestrutura do Ministério da Educação e na Resolução CME/BH no 001/2015, tais como aparelhos de televisão, som e outros. Assim, foram selecionadas dez variáveis de interesse para a pesquisa.

As variáveis de interesse, bem como a combinação de itens considerados no Censo estão apresentadas nos Quadros 1 e 2. Também são apresentados os valores atribuídos às combinações, sendo 2 (dois) pontos para infraestrutura do item considerada "adequada"; 1 (um) para "básica"; e 0 (zero) para "abaixo da básica". 


\section{U Us: Autibabat

ISSN: 1984-6444 | http://dx.doi.org/10.5902/1984644442721

condição de infraestrutura para a variável considerada "básica". Trinta e sete escolas tiveram sua condição quanto à Alimentação considerada "abaixo da básica": sete UMEls registraram não terem cozinha e nem refeitório, o mesmo ocorrendo em 30 escolas privadas, sendo duas delas conveniadas.

A análise das instalações e dependências escolares (Quadro 3) revela maiores desigualdades entre as escolas de educação infantil de Belo Horizonte.

Quadro 3 - Agrupamento de itens quanto às instalações e equipamentos

\begin{tabular}{|c|c|c|}
\hline $\begin{array}{c}\text { Variáveis de } \\
\text { interesse }\end{array}$ & Combinação das variáveis primárias & $\begin{array}{c}\text { Valor } \\
\text { atribuído }\end{array}$ \\
\hline \multirow{3}{*}{$\begin{array}{c}\text { (5) } \\
\text { Local de } \\
\text { funcionamento }\end{array}$} & Funciona em prédio próprio & 2 \\
\hline & Se o prédio é cedido ou alugado & 1 \\
\hline & Outros locais de funcionamento & 0 \\
\hline \multirow{3}{*}{$\begin{array}{c}(6) \\
\text { Sanitários }\end{array}$} & Banheiros para adultos, crianças, deficientes e chuveiro & 2 \\
\hline & Banheiros específicos para adultos e crianças & 1 \\
\hline & Não ter banheiro ou para adultos ou para crianças & 0 \\
\hline \multirow{3}{*}{$\begin{array}{c}(7) \\
\text { Dependências } \\
\text { administrativas }\end{array}$} & Diretoria, Secretaria e Sala de professores & 2 \\
\hline & Pelo menos duas dependências administrativas & 1 \\
\hline & Apenas uma ou nenhuma dependência administrativa & 0 \\
\hline \multirow{3}{*}{$\begin{array}{c}(8) \\
\text { Dependências } \\
\text { complementares }\end{array}$} & Almoxarifado, despensa e lavanderia & 2 \\
\hline & Pelo menos duas dependências complementares & 1 \\
\hline & Apenas uma ou nenhuma dependência complementar & 0 \\
\hline \multirow{3}{*}{$\begin{array}{c}(9) \\
\text { Áreas de recreação }\end{array}$} & Pátio, parque infantil e área verde & 2 \\
\hline & Pelo menos duas áreas de recreação & 1 \\
\hline & Uma ou nenhuma área de recreação & 0 \\
\hline \multirow{3}{*}{$\begin{array}{c}(10) \\
\text { Atendimento } \\
\text { Especializado }\end{array}$} & Dispõe de acessibilidade e sala de recursos & 2 \\
\hline & Ou acessibilidade ou sala de recursos & 1 \\
\hline & Sem acessibilidade e sem sala de recursos & 0 \\
\hline
\end{tabular}

Fonte: Duarte, Gomes e Gotelipe, 2019 (adaptada).

A maior parte das instituições de educação infantil da cidade, em 2018, funcionavam em prédios escolares. No entanto, 72 delas - todas privadas, sendo 16 conveniadas - apresentavam situação abaixo da básica quanto à variável. Desse total, duas funcionavam em salas de empresas, 19 funcionavam em templos de igrejas, três em casa de professores(as), duas em galpões e 46 em outros tipos de 


\section{F WEM \\ 15SN: 1984-6444

ISSN: 1984-6444 | http://dx.doi.org/10.5902/1984644442721

Por fim, a variável de interesse 10 avaliou a existência de espaços e acessos da escola adequados às crianças com deficiência ou mobilidade reduzida e sala de atendimento educacional especializado. Essa variável foi a que apresentou percentual mais baixo de adequação (2,4\%). Duas em cada três escolas privadas (68,0\% do total) não tinham recursos de acessibilidade e nem salas de recurso. Nas escolas públicas, o mesmo ocorria para $12,4 \%$ das escolas. Sobressai que em $82,4 \%$ das UMEls havia espaços acessíveis para crianças com deficiência em 2018, o que somente era verdade para $36,2 \%$ das escolas privadas, e para 19,6\% das escolas conveniadas.

Após a descrição das características de infraestrutura das escolas de educação infantil de Belo Horizonte a partir das dez variáveis de interesse, construiu-se um índice do Nível de Adequação de Infraestrutura (NAI), indo de 0 a 1. Ou seja, quanto mais o NAI de uma escola for próximo de 0 pior a infraestrutura dessa escola e quanto mais próximo de 1, melhor a infraestrutura. O NAl foi construído a partir da soma da pontuação em cada item, dividido por 20 (pontuação máxima). Dessa forma, foi possível estabelecer um grau de comparação entre as escolas de educação infantil de Belo Horizonte. A Tabela 4 revela que o grupo de escolas públicas, em seu conjunto, apresenta maior média de NAl em relação às escolas privadas.

Tabela 4 - Estatísticas descritivas do Nível de Adequação de Infraestrutura das escolas de educação infantil de Belo Horizonte, 2018

\begin{tabular}{lc|c|c|c|c|c}
\hline \multicolumn{1}{c}{ Escolas } & $\mathbf{n}$ & amplitude & mínimo & máximo & Média & CV \\
\hline Belo Horizonte (total) & 873 & 0,60 & 0,35 & 0,95 & 0,6947 & $16,7 \%$ \\
Escolas Públicas & 186 & 0,55 & 0,40 & 0,95 & 0,7075 & $13,9 \%$ \\
Escolas Privadas & 687 & 0,72 & 0,25 & 0,97 & 0,6913 & $17,4 \%$ \\
\hline
\end{tabular}

Fonte: Censo Escolar/ INEP, 2018

Na comparação dos dados desagregados por tipo de escola pública (Figura 3), é possível verificar que, em 2018, a maior média de NAl é de escolas exclusivas de educação infantil que não eram classificadas como UMEls. Apesar dessas escolas terem a mediana do NAI ligeiramente superior em relação a das escolas multietapas, não há diferença estatisticamente significativa entre elas $(U=221,500 ; p>0,05)$. Dentre as escolas públicas, as UMEls apresentam menor mediana, com diferença 


\section{WFM

ISSN: 1984-6444 | http://dx.doi.org/10.5902/1984644442721

significativa dos demais tipos $(U=1659 ; p<0,05$ em relação às escolas multietapas e $U=339 ; p<0,05$ em relação as escolas de educação infantil não classificadas como UMEI). As UMEIs e as escolas multietapas apresentam maior variabilidade de NAI.

Figura 3 - Boxplot dos NAl das escolas públicas de educação infantil de Belo Horizonte por tipo, 2018

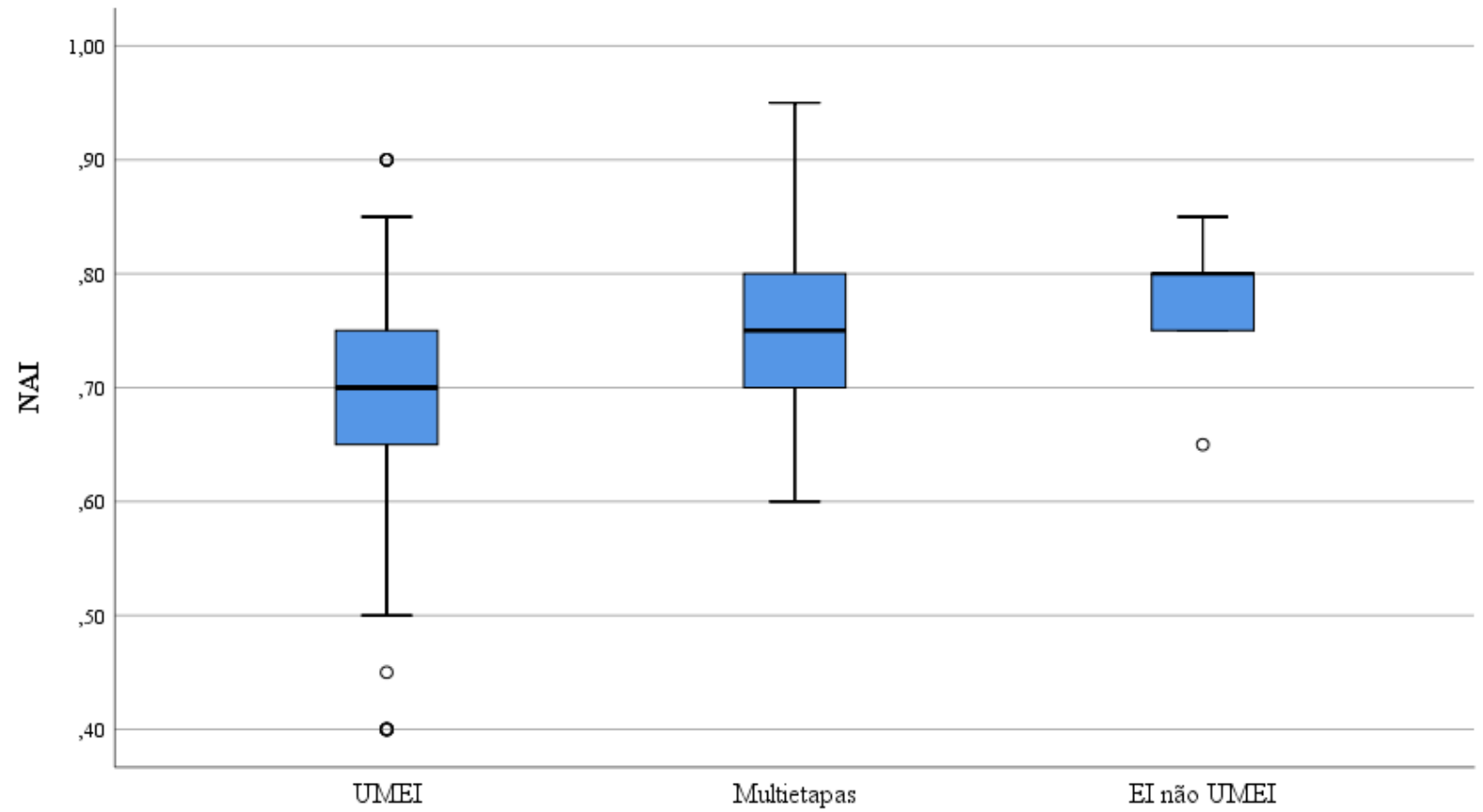

Fonte: Elaboração própria a partir do Censo Escolar/ INEP, 2018.

Uma possível explicação para esse resultado é que as escolas multietapas compartilham a infraestrutura do ensino fundamental, que historicamente teve políticas focalizadas por mais tempo. Já as escolas de educação infantil não classificadas como UMEls podem apresentar melhor NAI devido também ao fato de terem organização e prédios similares aos do ensino fundamental.

A comparação entre escolas não conveniadas e conveniadas (Figura 4) aponta que estas têm maiores níveis de adequação de infraestrutura e menor desigualdade interna. 


\section{HEM

ISSN: 1984-6444 | http://dx.doi.org/10.5902/1984644442721

Figura 4 - Boxplot dos NAl das escolas privadas de educação infantil de Belo Horizonte por situação de convênio, 2018

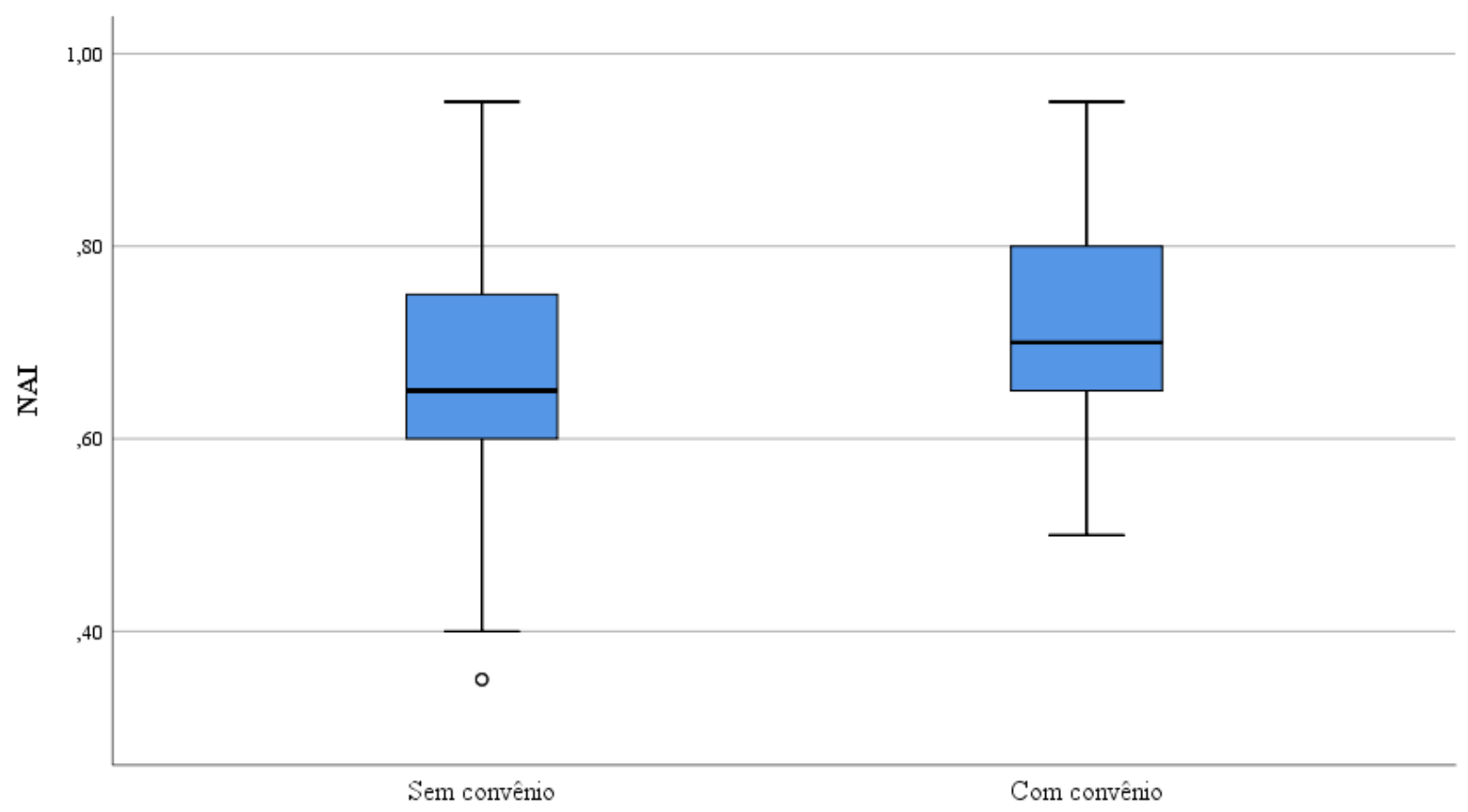

Fonte: Elaboração própria a partir do Censo Escolar/ INEP, 2018.

As médias das NAI das escolas de educação infantil das redes pública e privada estão territorialmente distribuídas da seguinte maneira: 


\section{تilloapão}

ISSN: 1984-6444 | http://dx.doi.org/10.5902/1984644442721

Figura 5 - Mapa temático de Belo Horizonte de Nível de Adequação de Infraestrutura das escolas de educação infantil públicas e privadas por UDH, 2018
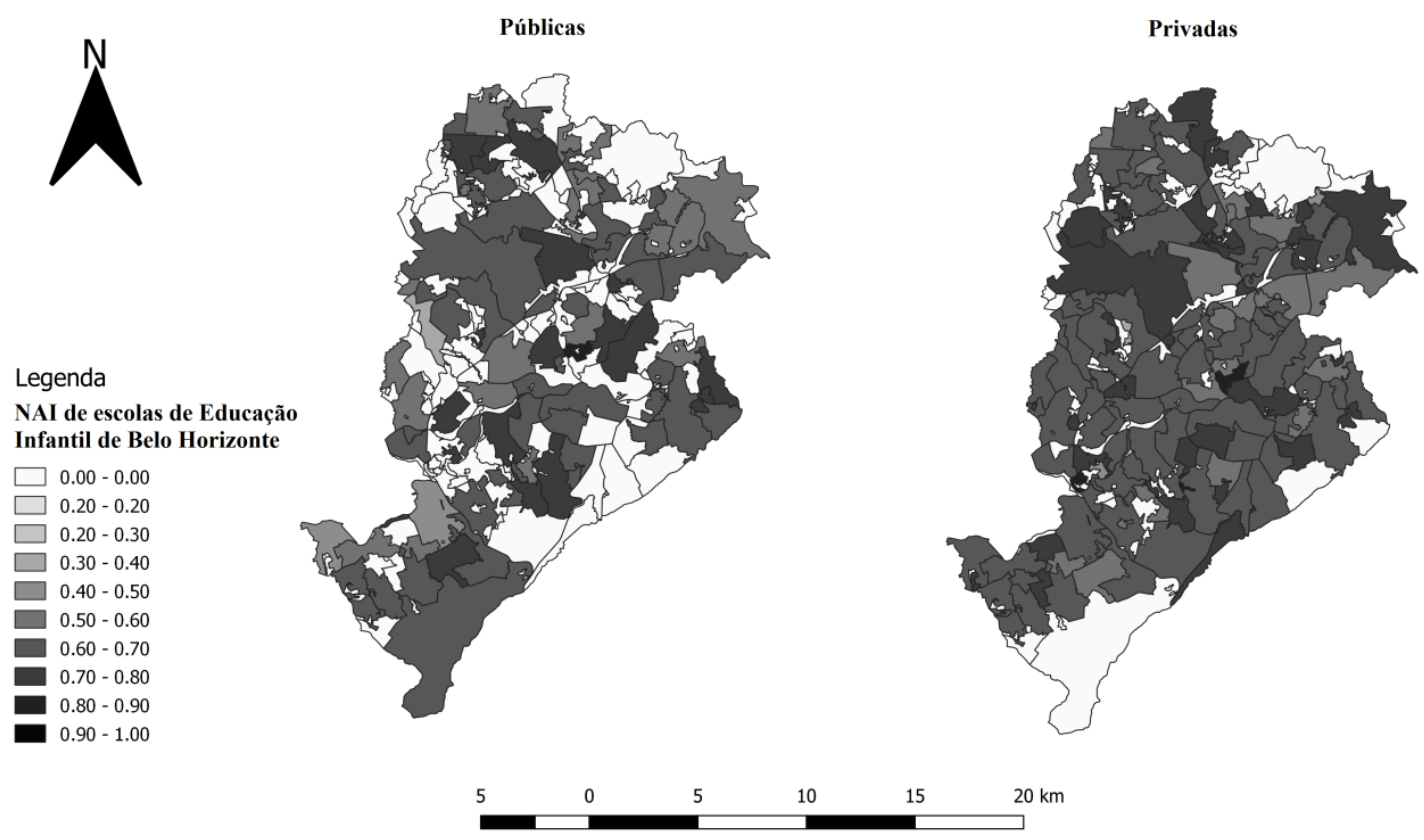

Fonte: Elaboração própria a partir do Censo Escolar/ INEP, 2018.

A dispersão territorial das NAl de escolas de educação infantil nas representações gráficas de Belo Horizonte não permite afirmar concentração de piores ou melhores indicadores de infraestrutura espacialmente na cidade.

\section{Considerações finais}

Por quase cinco décadas, de 1957 a 2003, as matrículas municipais da educação infantil em Belo Horizonte restringiam-se à faixa etária de quatro a seis anos, em horário parcial. Eram distribuídas entre as escolas municipais de educação infantil, as escolas municipais de ensino fundamental com turmas pré-escolares. Pode-se acrescentar também o atendimento prestado por instituições comunitárias e filantrópicas conveniadas com a Prefeitura Municipal de Belo Horizonte, pois recebedoras de recursos públicos. No que diz respeito à estrutura física, essas instituições apresentavam situações distintas, o que se pode conhecer por alguns 


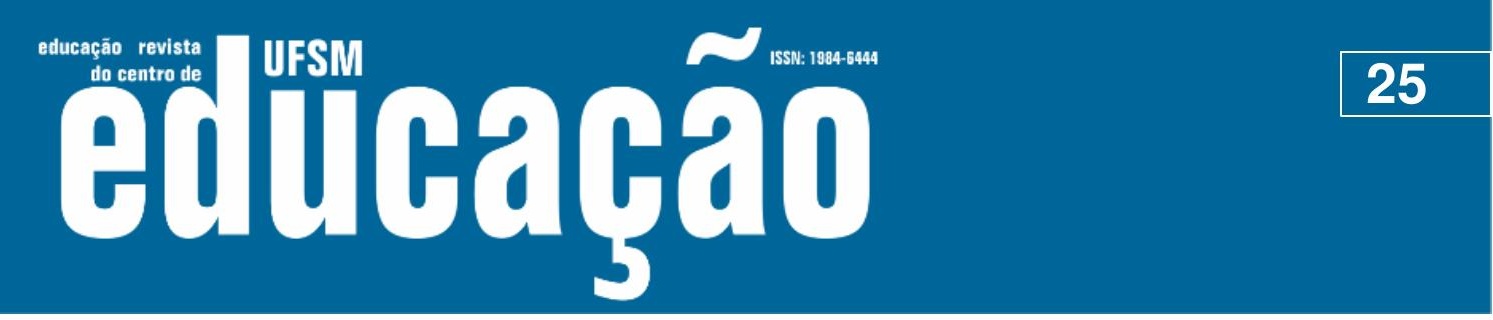

ISSN: 1984-6444 | http://dx.doi.org/10.5902/1984644442721

infraestrutura. Todavia, sabe-se que um dos questionamentos em relação a essas instituições é justamente não apresentarem uma estrutura adequada às necessidades de desenvolvimento das crianças pequenas, dado a sua característica de atender outras etapas de ensino além da educação infantil e crianças com idades acima de cinco anos. As UMEls por sua vez, conhecidas como instituições referência, inclusive pelo Ministério da Educação, apresentam o menor NAl dentre as escolas públicas, tendo também o maior grau de variação entre as instituições públicas, revelando que no universo das UMEls há desigualdades nas condições de infraestrutura, isto é, nem todas dispõem de uma estrutura adequada.

Mesmo considerando que a expansão da oferta da educação infantil no município de Belo Horizonte nas últimas décadas aconteceu na perspectiva de fortalecer o direito à educação das crianças pequenas, ainda é preciso um esforço por parte do poder público no sentido do cumprimento da Meta 1 do PNE/2014, sobretudo em se tratando das creches. Esse esforço se torna ainda mais evidente em relação à Meta 7 , no que se refere às condições físicas de oferta de uma educação infantil de qualidade. Tendo em vista tais resultados, fazem-se necessários prosseguir nos estudos sobre a adequação da infraestrutura das escolas de educação infantil, sobretudo das UMEls, a fim de se verificar in loco as condições de oferta, cotejandose esses estudos com as informações fornecidas pelo Censo Escolar.

\section{Referências}

ATLAS do Desenvolvimento Humano nas Regiões Metropolitanas Brasileiras. - Brasília: PNUD, Ipea, FJP, 2014.

\section{BELO HORIZONTE. CONSELHO MUNICIPAL DE EDUCAÇÃO. Resolução CME/BH № 01/2000. Disponível em:} http://portal6.pbh.gov.br/dom/iniciaEdicao.do?method=DetalheArtigo\&pk=880431. Acesso em: 19 jan. 2019.

BELO HORIZONTE. CONSELHO MUNICIPAL DE EDUCAÇÃO. Resolução CME/BH
$\begin{aligned} & \text { № } \\ & \text { 001/2015. Disponível }\end{aligned}$ http://portal6.pbh.gov.br/dom/iniciaEdicao.do?method=DetalheArtigo\&pk=1138760. Acesso em: 19 jan. 2019. 


\section{$=-1$ usm \\ 158N: 1884-6444}

ISSN: 1984-6444 | http://dx.doi.org/10.5902/1984644442721

SILVA, Isa Teresinha Ferreira Rodrigues da. O Processo de Constituição de Políticas Públicas de Educação infantil em Belo Horizonte: 1983 a 2000. 2002. 203 f. Dissertação (Mestrado em Educação) - Faculdade de Educação, Universidade Federal de Minas Gerais, Belo Horizonte, 2002.

TERRA, Cynthia Alessandra. A implementação do atendimento público de educação infantil em Belo Horizonte: processo e perspectivas. 2008. $218 \mathrm{f}$. Dissertação (Mestrado em Educação) - Faculdade de Educação, Pontifícia Universidade Católica, Belo Horizonte, 2008.

VEIGA, Márcia Moreira. Creches e políticas sociais. 2005. Disponível em: https://books.google.com.br/books?id=TdbEQ0utzRIC\&printsec=frontcover\&hl=ptBR \&source=gbs_ge_summary_r\&cad $=0 \# v=0$ nepage\&q\&;=false. Acesso em: 30 out. 2019.

VIEIRA, Lívia M. Fraga. Educação infantil no município de Belo Horizonte: histórico e situação atual. 1998. Relatório de pesquisa. (mimeo)

\section{(@) $(1) \Theta$}

This work is licensed under a Creative Commons Attribution-NonCommercial 4.0 International (CC BY-NC 4.0) 